\title{
Pokok-Pokok Bahasan Kebahasaan dalam Kajian Antropologi Bahasa
}

\author{
Hendarto Supatra \\ Fakultas Ilmu Budaya Undip Semarang \\ Email: hendartosupatra53@gmail.com
}

\begin{abstract}
Linguistic anthropology or ethnolinguistics is a branch of anthropology with language in use or speech as it's object of study. In another way it is the study of a language as a cultural resource and speaking as a cultural practice. This science with such a definition can be traced back to the Sapir and Whorf hypothesis, concerning with theory of linguistic relativity and theory of linguistic determinism. It is a matter of conceptual world based on perception or more specific a representation of reality (real world). Linguistic anthropology with such a focus of study no need to be done only in primitive society but in modern society as well and in internal language since there are many sub-societies in a language society. The method in this study is what is called thick description that must be carried out using grounded research. The issues and topics that are at the core of this research such as the politics of representation, the legitimation of power, the cultural basis of racism and ethnic conflict, the relationship between ritual performance and the forms of social control, speech in ceremonies, ritual, meeting, and so on.
\end{abstract}

Keywords: linguistic anthropology, language relativity, language determinism, sign system

\section{Intisari}

Antropologi bahasa atau antropologi linguistik atau etnolinguit adalah cabang antropologi dengan bahasa yang digunakan atau berpidato sebagai objek studi. Dengan cara lain, ini adalah studi tentang bahasa sebagai sumber budaya dan berbicara sebagai praktik budaya. Ilmu pengetahuan ini dengan definisi semacam itu dapat ditelusuri kembali ke hipotesis Sapir dan Whorf, berkenaan dengan teori relativitas linguistik dan teori determinisme linguistik. Ini adalah masalah dunia konseptual yang tertuju pada persepsi atau representasi relualitas yang lebih spesifik (dunia nyata). Antropologi linguistik dengan fokus kajian seperti itu tidak perlu dilakukan hanya dalam sosiokultural primitif tapi juga masyarakat modern dan bahasa internal karena ada banyak subsektivitas dalam masyarakat bahasa. Metode dalam penelitian ini adalah apa yang disebut deskripsi tebal yang harus dilakukan dengan menggunakan grounded research. Isu dan topik yang menjadi inti penelitian ini seperti politik representasi, legitimasi kekuasaan, basis budaya rasisme dan konflik etnis, hubungan antara pertunjukan ritual dan bentuk kontrol sosial, pidato dalam upacara, ritual , Rapat, dan sebagainya.

Kata kunci: antropologi linguistik, relativitas bahasa, determinisme bahasa, sistem tanda 


\section{Pendahuluan}

Antropologi bahasa merupakan padanan linguistic anthropology dalam bahasa Inggris. Di Amerika bidang studi yang diberi label linguistic anthropology ini kadang juga disebut anthropological linguistics. Di Eropa, kajian yang hampir sama dengan antropologi bahasa dikenal sebagai ethnolinguistik atau ethnolinguistics ( Bandingkan Duranti. 1997: 2 ). Lalu apakah yang menjadi kekhasan disiplin ini? Apa bedanya dengan sosiolinguistik atau cabang-cabang ilmu bahasa yang lain?

Jawaban yang paling sederhana dari disiplin ini atas pertanyaan di atas ialah bahwa antropologi bahasa ini merupakan cabang dari anthropologi yang pokok kajiannya berupa bahasa. Hal ini mudah dipahami karena bahasa merupakan salah satu fenomena kebudayaan dan kebudayaan itulah objek kajian anthropologi. Koentjaraningrat ( 1985: 2 ) menulis bahwa isi kebudayaan yang bersifat universal itu meliputi: (1) sistem religi dan upacara keagamaan, (2) sistem dan organisasi kemasyarakatan, (3) sistem pengetahuan, (4) bahasa, (5) kesenian, (6) sistem mata pencaharian hidup, dan (7) sistem teknologi dan peralatan.

Hymes ( 1963: 277 ), misalnya, mendefinisikan disiplin ini sebagai " the study of speech and language within the context of anthropology ". Lalu seperti apa atau bagaimana kajian bahasa dalam kerangka antropologi ini dikerjakan? Barang kali bisa dikatakan, batasan ilmu antropologi bahasa ini menjadi lebih spesifik lagi ketika Alessandro Duranti dalam bukunya yang diberi judul Linguistic Anthropology, menulis sebagai berikut: “ ... in this book linguistic anthropology will be presented as the study of language as a cultural resource and speaking as a culture practice" ( loc cit ).

Dalam tradisi linguistik Indonesia terdapat istilah sosiolinguistik, psikolinguistik, neurolinguistik, sehingga banyak yang menduga bahwa tentu ada istilah antropolinguistik pula. Cukup menarik untuk dicatat, bahwa istilah tersebut tidak terdapat dalam Kamus Linguistik yang disusun oleh Kridalaksana ( 1983 ). Alih-alih antropolinguistik, di dalam satu-satunya kamus linguistik yang berbahasa Indonesia itu terdapat istilah etnolinguistik di samping istilah linguistik antropologi. Untuk lebih jelasnya, berikut ini kutipan tulisan Kridalaksana ( 1983: 42 ) secara utuh tentang etnolinguistik: (1) cabang linguistik yang menyelidiki hubungan antara bahasa dengan masyarakat pedesaan atau masyarakat yang belum mempunyai tulisan ( bidang ini juga disebut linguistik antropologi ); (2) cabang 
linguistik antropologi yang menyelidiki hubungan bahasa dan sikap bahasawan terhadap bahasa; salah satu aspek etnolinguistik yang sangat menonjol ialah masalah relativitas bahasa. Tulisan ini masih akan kembali membahas soal peristilahan ini pada subbab berikutnya nanti.

Di dalam Longman Dictionary of Applied Linguistics susunan Richards, Plat, dan Weber ( 1985 ), tidak didapatkan istilah ethnolinguistics atau antropolinguistics, melainkan, yang ada, adalah anthropological linguistics ( hal. 13 ). Di dalam kamus ini anthropological linguistics didefinisikan sebagai berikut, " a branch of linguistics which studies the relationship between language and culture in a community. Eg its traditions, beliefs, and family structure “. Berikut ini satu kamus lagi dipilih untuk dibahas pendapatnya sehubungan dengan seluk-beluk antropologi bahasa dalam bahasan ini. Kamus yang dimaksud adalah Dictionary of language and Linguistics (1996) yang ditulis oleh Bussmann yang diterjemahkan oleh Trauth dan Kazzazi. Adapun judul aslinya dalam bahasa Jerman adalah Lexikon der Sprachwissenschaft (1990 ). Di dalam kamus ini didapatkan istilah ethnolinguistics yang adalah sinonim dari neo-Humboldtianisme. Berikut adalah kutipan lengkap, pengertian ethnolingistic dalam kamus ini.

Collective term for anthropological and linguistic investigation into the connections between language and ethnically based, sociocultural aspects of the given linguistic community. Most works in ethnolinguistics can be traced to the linguistic philosophy of Wilhelm von Humboldt ( 1767-1835: 155 ).

Berdasarkan tiga kamus tersebut di atas, meskipun tidak sulit untuk menemukan benang merah yang menghubungkan satu dengan yang lain, perihal relasi antara linguistik dan antropologi akan tetapi juga mesti diakui bahwa peristilahan yang digunakan dan pengertiannya masih perlu dibuat menjadi lebih jelas. Setidaknya pantas dipertanyakan apakah kajian yang berkaitan dengan relasi antara bahasa dan budaya ini termasuk ke dalam ilmu bahasa atau linguistik atau betul-betul sebuah wilayah interdisipliner, atau termasuk ke dalam wilayah ilmu budaya atau antropologi? Ketika perihal tersebut telah menjadi jelas atau setidaknya telah dibuat menjadi jelas, barulah bisa ditentukan pokok bahasan-pokok bahasan yang ada di dalamnya, setidaknya demikianlah menurut pendapat saya.

\section{Linguistik, Sosiolingistik, dan Antropologi Bahasa}


Di dalam semiotik yakni ilmu yang berurusan dengan tanda dan seluk-beluk yang berkaitan dengan tanda, baik tanda verbal maupun nonverbal --dalam pengertian ini ilmu bahasa atau linguistik bisa dikatakan sebagai cabang semiotik-- didapatkan tiga cabang atau subbidang semiotik ( Fiske, 1982: 43 ) yakni sintaksis (yang meliputi morfologi juga), semantik, dan pragmatik. Sintaksis mengkaji sistem yang mengatur hubungan antartanda, semantik mengkaji hubungan antara tanda dengan makna atau tanda dengan realitas yang dirujuknya, sedangkan pragmatik mengkaji hubungan antara tanda dengan pengguna tanda. Dengan kata lain sintaksis dan semantik adalah cabang semiotik yang berurusan dengan sistem tanda atau dalam lingkup linguistik, berupa bahasa (bunyi ujar) sebagai sistem tanda, sedangkan pragmatik berurusan dengan sistem tanda dalam penggunaan. Yang pertama oleh Saussure disebut la langue sedangkan yang kedua disebut la parole. Tegasnya, linguistik itu berurusan dengan la langue.

Linguistik mengkaji la langue, aspek sosial bahasa, yang sebenarnya adalah fonem, morfem, kata, frasa, dan klausa atau kalimat. Teks tidak termasuk kajian linguistik. Teks bukanlah satuan linguistik di atas kalimat. Satuan lingual atau bentuk lingual atau ekspresi yang tidak lain adalah fonem sampai kalimat tadi berbeda dengan teks bukan secara kuantitatif melainkan secara kualitatif; teks bisa berupa sebuah kata atau sebuah kalimat. Teks adalah sistem tanda (bahasa) dalam penggunaan yang adalah objek kajian pragmatik atau kajian wacana. Hal ini perlu dikemukakan sebab hingga saat ini masih ada juga orang yang tidak menyadari hal tersebut.

Linguistik mengkaji la langue, lalu bagaimana dengan sosiolinguistik? Memasuki wilayah ini sejauh yang diketahui, masih terdapat perbedaan persepsi. Sosiolinguistik juga berurusan dengan la langue, hanya saja di dalam telaahannya itu memperhitungkan, secara eksplisit, pengaruh situasi tutur dan latar belakang penutur. Lebih jelasnya, dalam rangka menjelaskan (mengeksplanasi) satuan-satuan lingual diperhitungkan pula perihal ragam bahasa, ediolek, dialek, sosiolek, tingkat tutur, dan register. Kajian bahasa sebagaimana yang lazim dilakukan oleh sosiolinguis itu oleh Labov (1966) dianggap sebagai kritik terhadap linguistik struktural yang dianggapnya telah lalai dalam hal yang sewajarnya sajalah memperhitungkan situasi dan latar belakang penutur dalam mendeskripsi dan mengeksplanasi stuan-satuan lingual. Sejalan dengan pandangan ini, Oetomo (1987), pakar 
sosiolingistik yang termasuk ke dalam deretan kelas atas dalam keilmubahasaan di Indonesia itu, menulis sebagai berikut.

Pada hemat saya, karena bahasa merupakan suatu bentuk perilaku sosial yang selain digunakan untuk berkomunikasi (yang notabene melibatkan setidaknya dua orang) juga mempunyai fungsi sosial budaya, pengkajian terhadap bahasa manusia semestinya tidak hanya menelaah struktur bahasa terlepas dari manusia yang menuturkannya beserta budaya dan masyarakat tempat ia berada. Dengan demikian, segala kegiatan penelaah terhadap bahasa manusia seyogyanya digolongkan ke dalam disiplin linguistik (dalam Dardjowidjojo, 1987: 161).

Demikianlah, apabila diikuti jalan pikiran para sosiolinguis pada umumnya, maka apa yang lazim disebut linguistik (struktural) itu mencakupi pula kajian bahasa yang dikerjakan oleh Labov dan rekan-rekannya. Dan, telaah bahasa dalam jenis ini merupakan sebagian saja dari ilmu yang disebut sosiolinguistik. Artinya, apa yang disebut sosiolinguistik tidak hanya mengkaji satuan-satuan lingual seperti yang dipelopori oleh Labov (1966) (Bandingkan Poedjosoedarmo, 1987: 8). Mengacu pada tulisan Oetomo yang telah disebut di atas, subbidang yang lain dalam sosiolinguistik ini adalah etnografi komunikasi atau etnografi pertuturan (ethnography of speaking). Gamperz dan Hymes (1972: vii) melihat adanya kompetensi komunikasi yang harus ada pada penutur bahasa untuk memungkinkan seseorang bisa berkomunikasi dengan lancar dan wajar. Kompetensi komunikasi ini menurut mereka berdua ini adalah "what a speaker needs to know to communicate effectively in culturally significant settings" (Lihat Oetomo, 1987: 162). Lebih lanjut, mengutip Labov (1972: 84), Oetomo melihat tujuan etnografi pertuturan sebagai berikut.

Jadi etnografi pertuturan berupaya memberikan dan menganalisis pola pola penggunaan bahasa atau ragam-ragam bahasa dalam budaya tertentu seperti, misalnya, bentuk-bentuk pertuturan, kaidah-kaidah pemilihan yang tepat oleh penutur, antarhubungan penutur, pendengar, pengamat (audience), pokok, saluran, suasana (setting), dan cara-cara bagaimana penutur memanfaatkan sumber-sumber yang dipunyai bahasanya untuk menjalankan fungsi-fungsi tertentu.

Subbidang sosiolinguistik yang ketiga adalah yang sering disebut sosiolinguistik makro atau sosiologi bahasa yang kekhususannya terletak pada soal interaksi antara penggunaan bahasa dan pengorganisasian bahasa oleh masyarakat atau lebih spesifiknya, menurut Fishman (1972b: 45) yang dikenal sebagai pakar sosiologi bahasa ini, subbidang 
ini membahas hal-hal yang berkaitan dengan penggunaan bahasa tertentu dalam konteks tertentu, sikap bahasa, perilaku terhadap bahasa, dan terhadap pemakai bahasa. Di dalam sosiologi bahasa ini pulalah dibicarakan perihal kedwibahasaan, kontak bahasa, kepunahan bahasa, dan juga perencanaan bahasa.

Di dalam tiga kamus linguistik yang dikutip di atas, tidak terdapat istilah antropolinguistik, padahal terdapat sosiolinguistik, psikolinguistik, neurolinguistik, dan yang lain. Hal yang demikian ini sebenarnya dikarenakan oleh kenyataan bahwa membedakan atau menarik garis batas yang tegas antara gejala sosial dengan gejala budaya itu memang tidak mudah. Inilah sebabnya, awal-awal ketika muncul tulisan-tulisan yang sekarang ini lazim dikategorikan ke dalam sosiolinguistik, sebenarnya, beberapa di antaranya, lebih tepat disebut antropolinguistik. Dipilihnya istilah sosiolinguistik dan bukan antropolinguistik itu ya karena yang pertama pada waktu itu lebih sering digunakan dan lalu yang terjadi adalah semata-mata konvensi belaka. Peodjosoedarmo (1987: 9 - 10) berkomentar sebagai berikut.

Dari satu segi, buku yang terbit pada tahun-tahun itu menunjukkan keraguannya akan materi penelitian serta metodologinya. Terkadang terkilas bahwa makalah itu membahas hal-hal yang seharusnya dibahas di dalam ilmu antropologi, ethnologi, atau di bidang yang kurang jelas statusnya. Namun demikian, hal yang bermula dengan sesuatu yang agak meragukan ini lalu berkembang menjadi apa yang sekarang ini kita sebut sosiolinguistik.

Berdasarkan uraian Oetomo di atas, tentang tiga subbidang sosiolinguistik, maka sebenarnya hanya satu subbidang saja yang benar-benar bisa digolongkan ke dalam ilmu bahasa atau linguistik yakni studi tentang kebahasaan yang dianggap substansial (= fonem, morfem, kata, frasa, klausa, kalimat) yang melibatkan konteks situasi dan latar belakang penutur. Khusus untuk cabang ini Labov pernah usul agar diberi nama linguistik saja (ibid. hal 10). Sementara itu, apa yang lazim disebut sosiolinguistik makro atau sosiologi bahasa sebenarnya berada antara sosiologi bahasa dan antropologi bahasa, sedangkan etnografi pertuturan, menurut pendapat penulis, cenderung termasuk ke dalam antropologi bahasa, meskipun sementara orang barangkali akan setuju akan tetapi dengan catatan, yakni itu berlaku pada masyarakat pedesaan atau istilah Kridalaksana dalam kamus linguistiknya, secara lebih spesifik dikatakan, untuk masyarakat yang belum mengenal tulisan. Richard (dkk) dalam kamusnya yang juga dikutip di atas, menyatakan “... the relationship between 
language and culture in a community, eg its tradition, beliefs, and family structure", tanpa embel-embel masyarakat pedesaan.

\section{Hipotesis Humboldt, Sapir, dan Whorf}

Demikianlah, setidaknya dari sudut pandang tertentu, terdapat (1) ilmu bahasa yang mengkaji bahasa sebagai sistem tanda dan (2) ilmu bahasa yang mengkaji bahasa sebagai sistem tanda dalam penggunaan. Saussure yang dianggap sebagai bapak linguistik itu, adalah orang yang melihat substansi bahasa atau fakta sosial bahasa atau la langue yang notabene independen, dan linguistik struktural ini bertujuan untuk mengungkap hakikat fakta soaial bahasa atau la langue. Hal yang menarik ialah bahwa untuk mendeskripsikan dan tentu saja mengeksplanasikan fonem dan fonotaktiknya, morfem dan morfotaktiknya, frasa, klausa dan kalimat berikut valensi sintaksisnya, hanya akan tuntas ketika linguis melibatkan variabel penjelas yang didapat dari sosiologi, antropologi, psikologi, neurologi, dsb. bahkan dari --ini merupakan variabel sangat penting-- linguistik diakronik dan linguistik kontrastif (Bandingkan Poedjosoedarmo, 1987: 8). Jenis yang kedua yang oleh Saussure tidak dianggap termasuk ke dalam hakikat bahasa, adalah apa yang oleh Charles Sanders Peirce disebut pragmatik yang meliputi juga kajian wacana (teks) (Bandingkan Fiske, 1982: 43; Zoest, 1993: 3; Panuti dan Zoest, 1996: 5 - 6).

Terpisah dari soal bahasa sebagai tanda dan seluk beluk yang berkaitan dengan tanda berikut hal-hal yang berkaitan dengan penggunaan tanda, adalah kegiatan pengamatan dan penelitian bahasa yang fokus pada perbedaan bahasa satu dengan bahasa lain dan dampak dari perbedaan tersebut atas persepsi orang terhadap realitas (Lihat Ishtla Singh dalam Thomas dan Wareing, 2007: 37). Bahasa sebagai pokok kajian dalam tradisi ini dipelopori oleh para antropolog, dan tentu saja menggunakan kerangka kerja antropologi. Mereka itu antara lain adalah Edward Sapir dan Benjamin Lee Whorf. Dan rupanya inilah cikal-bakal kajian relativitas bahasa yang oleh Kridalaksana disebut sebagai aspek yang sangat menonjol dalam kajian ethnolinguistik atau antropologi bahasa.

Memang benar bahwa bahasa atau yang tak lain dan tak bukan adalah pengetahuan, merupakan hasil usaha manusia untuk mengetahui, memahami, dan 
mengkomunikasikannya dengan sesamanya demi pemahaman yang lebih luas dan lebih mendalam akan apa saja yang bisa atau mungkin bisa untuk diketahui dan tentu hal yang demikian itu berangkat dari realitas yang kongkrit dengan menggunakan pertandaan. Walhasil dari semuanya itu lalu manusia, sesungguh-sungguhnya, hidup dalam dua dunia atau realitas: realitas konvensional dan realitas mendalam. Lewat panca indra dan olah pikiran, manusia bersentuhan dengan realitas mendalam tetapi alam kesadaran manusia adalah alam kesadaran konvensional. Grigg di dalam bukunya The Tao of Being (1994: xiii) menulis sebagai berikut.

Anyone who thoughtfully uses language should realize that words are not a replication of experience but a representation. Language does not replicate experience although it may replicate what is thought to have been experience, which is quite another thing. Words always create vicariousness.

Ciri relativitas bahasa hampir tak mungkin bisa dipisahkan dari ciri diterminatif bahasa. Dengan kata lain di sini hendak dikatakan bahwa manusia hidup dalam dunianya masing-masing yakni dunia konseptual atau dunia kebahasaannya. Grigg berdasarkan kutipan di atas, lalu juga antropolog terkenal yakni Charles H. Kraft di dalam bukunya yang berjudul Christianity in Culture, A Study in Dynamic Biblical Theologizing in CrossCulturel Perspective (1990: 53), dapat digolongkan ke dalam Neo-Humboldtian. Ingat bahwa etnolingistik di dalam Dictionary of Language and Linguistics karya Bussmann merupakan sinonim dari neo-Humboldtianisme. Mengapa disebut demikian? Ya karena Wilhelm von Humboldt sang filsuf bahasa dari Jerman ini boleh disebut sebagai peletak dasar dari etnolinguistik. Wierzbicka (1992: 5) menulis, "Profound semantic differences between languages were also emphesised by Wilhelm von Humboldt, who saw different languages as bearers of different cognitive perspectives, different worldviews". Kemudian pada halaman berikutnya dikatakan, "In fact, Humboldt goes so far as to suggest that there are very few words in any language which do have exact equivalents in other languages". Dan pandangan yang pada prinsipnya sama juga dikemukakan oleh Sapir (1949: 162) yang antara lain menulis bahwa "Human beings do not live in the objective world alone, but are very much at the mercy of the particular language which has become the medium of expression for their society". Lalu lebih lanjut dikatakannya bahwa, "The fact of the matter is that the "real world" is to a large extent unconsciously built up on the language habits of the group“. Hal yang pada prisipnya sama juga dikemukakan oleh penerus Sapir yakni 
Whorf yang antara lain menulis, "Language is not merely a reproducing instrument for voicing ideas but rather is itself the shaper of ideas, the progam and guide for the individual's mental activity, for his analysis of impressions, for his synthesis of his mental stock in trade .... We dissect nature along line laid down by our native language " (1956: 13; Kraft, 1990: 53).

Dengan mengikuti pemikiran Humboldt, Sapir, Whorf, dan Kraft, sebenarnya hanya hendak diyakinkan akan adanya ladang penelitian yang sangat menarik sekaligus bermanfaat perihal kekayaan yang dimiliki oleh umat manusia dikarenakan oleh perbedaan-perbedaan pada berbagai masyarakat bahasa dalam mempersepsi dan mengonseptualisasi bahkan mensistematisasi realitas objektif yang mereka alami. Menarik untuk sekedar tambahan catatan bahwa temuan para antropolog tersebut sebenarnya telah disadari/diketahui oleh tokoh-tokoh di zaman poros (aksial), setidaknya oleh Lao Tse (Grigg. 1994: xiii ), maupun Sidharta Gautama (Budha) (Gragnani. 2006: 5). Demikianlah, bahasa menyodorkan pandangan hidup yang tidak bisa ditolak, jadi bersifat diterministik, kecuali, dan inilah satu-satunya cara, orang berpindah ke bahasa lain.

\section{Bahasa sebagai Sumber dan Tuturan sebagai Realisasi}

Bahasa (langue) dalam istilah Saussure adalah papan catur, bidak-bidak catur, dan seperangkat peraturan untuk bermain catur. Ketika orang hendak bermain catur maka dia harus menggunakan papan catur, bidak-bidak catur, dan mengikuti cara bermain catur. Tuturan (la parole) adalah realisasi yang bersifat individual atas bahan dan aturan-aturan sebagai persyaratan untuk bermain catur. Oleh karena kebudayaan tidak lain dan tidak bukan adalah dunia riil tempat manusia pemilik kebudayaan tersebut hidup berinteraksi dengan menggunakan tanda-tanda untuk menerima dan memberi informasi melalui antara lain dan terutama sistem tanda yang adalah bahasa bunyi ujar, maka benarlah yang dinyatakan oleh Duranti (1997: 2) bahwa linguistic anthropology adalah, "the study of language as a cultural resource and speaking as a cultural practice." Dengan definisi semacam ini Duranti telah mengembangkan pengertian antropologi bahasa sebagai "the study of speech and language whitin the context of anthropology" (Hymes, 1963: 277), yang cenderung diartikan sebagai kajian tentang hubungan antara bahasa dengan masyarakat pedesaan yang belum mempunyai tulisan, tentang kekhasan masyarakat dalam kinship terminology, tentang bagaimana orang-orang berkomunikasi dalam peristiwa sosial 
budaya tertentu seperti upacara-upacara adat, pertemuan-pertemuan adat yang menggunakan varian bahasa yang khas, meluas ke pemakaian bahasa di kota-kota yang paling modern sekalipun.

Duranti, pakar antropologi bahasa ini, dengan membatasi antropologi bahasa sebagai kajian atas bahasa sebagai sumber untuk orang berpikir, bertutur dan bertindak dalam masyarakat bahasa tertentu dan tuturan sebagai realisasi kebudayaan, yakni bermain catur yang dikendalai oleh papan catur, bidak-bidak catur dan seperangkat peraturan bermain catur, maka menjadi luaslah cakupan kajian disiplin ini. Sebab dengan demikian antropolog bahasa tidak hanya membatasi wilayah kerjanya di pedesaan yang belum mengenal tulisan. Tentu saja, meskipun menjadi luas sudah cakupan wilayah kajian antropologi bahasa, disiplin ini, demikian menurut Duranti (1997: 4), hanyalah salah satu cabang antropologi. Tiga cabang lainnya adalah archaeological anthropology, biological or physical anthropology, dan sociocultural anthropology. Akhirnya, tokoh utama bidang antropologi bahasa saat ini, Duranti, telah pula mencoba memetakan pokok-pokok bahasan dalam bidang ini, sebagai berikut, "the politics of representation, the constitution of authority, the legimitation of power, the cultural basis of racism and ethnic conflict, the process of socialization, the cultural construction of the person (or self), the politics of emotion, domain specific knowledge and coqnition, artistic performance and the politics of aesthetic consumtion, culture contect and social change“ (1997: 4).

Pada awalnya, ketika orang berbicara tentang antropologi bahasa maka yang segera mulcul dalam ingatan adalah pekerjaan Edward Sapir (1884 - 1939), Benjamin Lee Whorf (1897 - 1941) di benua Amerika, Bronislaw Malinowski yang bekerja sebagai antropolog, mempelajari kehidupan masyarakat pulau Trobriand, masyarakat primitif yang terletak tidak jauh dari benua Australia, dengan menggunakan bahasa masyarakat setempat dan terlibat jauh ke dalam kehidupan mereka sehari-hari, dalam kurun waktu empat tahun (Pals, 2012: 283). Inilah sebabnya mengapa orang cenderung mengasosiasikan kerja antropologi bahasa dengan masyarakat pedesaan (primitif) yang belum mengenal tulisan. Padahal ada yang lebih penting untuk diperhatikan sebagai buah utama dari kerja mereka, yakni konsep relativitas dan diterminisme bahasa. Menurut teori relativitas bahasa ini, tiaptiap masyarakat budaya akan merepresentasikan dunia dengan cara yang berbeda-beda dan perbedaan-perbedaan itu terkodekan pada masing-masing bahasa. Menurut teori 
diterminisme bahasa, di samping persepsi orang akan dunia itu mempengaruhi bahasa, yang lebih signifikan ialah bahwa bahasa yang digunakan seseorang itu mempengaruhi secara mendalam cara orang tersebut mempersepsi dunia. Dua macam teori ini, yang sebenarnya merupakan esensi dari hipotesis Sapir-Whorf ini sebenarnya juga sudah dikemukakan oleh Wilhelm von Humboldt (Wierzbicka, 1992: 3). Nah, ketika esensi hipotesis Sapir-Whorf tersebutlah yang menjadi cirri kerja antropologi bahasa maka penelitian dengan menggunakan disiplin ini memang tidak lagi perlu dibatasi hanya pada masyarakat pedesaan. Yang kedua, soal representasi dan diterminisme ini tidak hanya berlaku antarbahasa melainkan juga interbahasa. Sepertinya lewat alur berpikir semacam inilah maka setiap teks atau wacana atau bahasa dalam pemakaian, selalu dikendalai oleh semacam relativitas dan diterminisme, sebagaimana yang terjadi pada lintas bahasa.

Akhirnya perlu diperhatikan pula, sebagai penelitian dalam wilayah disiplin antropologi, di sini metode yang diandalkan bukanlah metode eksperimen yang layak digunakan dalam ilmu pasti. Bagaimana pun penelitian yang berurusan dengan tanda dan pertandaan haruslah mengandalkan pada metode pelukisan mendalam atau thick description. Tugas utama seorang peneliti, demikian menurut Geertz (Pals, 2012: 338) tidak hanya sebatas mendeskripsikan/melukiskan struktur suku-suku primitif atau bagianbagian ritual, melainkan untuk mencari makna, menemukan apa yang sesungguhnya ada di balik perbuatan seseorang, makna yang ada di balik seluruh kehidupan dan pemikiran ritual, struktur dan kepercayaan mereka. Dan itu hanya mungkin dilakukan lewat metode pelukisan mendalam.

\section{Simpulan}

Pokok-pokok kajian dalam antropologi bahasa adalah bahasa dalam pemakaian atau teks atau wacana, dan fokusnya ada pada soal representasi dunia yang dikendalai oleh relativitas dan diterminisme, baik pada tataran bahasa maupun pada tataran subsubkelompok masyarakat dalam satu bahasa tertentu. Penelitian semacam ini tidak lagi terbatas pada masyarakat pedesaan yang belum mengenal system tulisan. Penelitian dalam masyarakar modern bisa menggunakan disiplin antropologi bahasa sebagaimana disarankan oleh Duranti (1997). 
Tentu saja objek penelitian yang berupa bahasa dalam penggunaan ini bisa dilakukan lewat berbagai disiplin ilmu, pragmatik misalnya atau sosiolinguistik atau kajian teks atau wacana. Dan besar peluangnya untuk terjadinya kerja lintas disiplin atau interdisipliner.

\section{Daftar Pustaka}

Bussmann, Hadumond. 1996. Dictionary of Language and Linguistics. London: Routledge.

Dardjowidjojo, Sunjono (Peny.) Linguistik: Teori dan Terapan. Jakarta: Lembaga Bahasa Univ. Katholik Atma Jaya.

Fiske, John. 1982. Introduction to Communication Studies. New York: Methuen \& Co. LTD.

Gragnani, Carlo. 2006. Birth, Life and Death of the Ego. Sri Lanka: Budhis Publication Society.

Grigg, Ray, 1994. The Tao of Being, Lao Tzu's Tao Te Ching Adapted for a anew Age. Singapore: SS Mubaruk \& Brothers PTE. LTD.

Kraft, Charles H. 1990. Christianity in Culture, A Study in Dynamic Biblical Theologizing in Cross-Culture Perspective. New York: Orbis Books.

Kridalaksana, Harimurti. 1983. Kamus Linguistik. Jakarta: Gramedia.

Oetomo, Dede. 1987. “ Linguistik dan Sosiolinguistik: Dua Ancangan Terhadap Bahasa Manusia” dalam Dardjowidjojo, Sunjono . 1987.

Pals, Daniel L. 2011. Seven Theories of Religion. Jogjakarta: IRCiSoD.

Santoso, Anang. 2012. Studi Bahasa Kritis, Menguak Bahasa Membongkar Kuasa. Bandung: Mandar Maju.

Sapir, Edward. 1949. Selected writings of Edward Sapir in Language, Culture and Personality. Ed. David Mandelbaum. Berkely: University of California Press.

Thomas, Linda \& Wareing, Shan. 2007. Bahasa, Masyarakat \& Kekuasaan. Yogyakarta: Pustaka Pelajar.

Whorf, Benjamin Lee. 1956. Language, thought, and Reality: Selected Writing of Benjamin Lee Whorf. (Ed. John B. Carroll). New York: Wiley.

Wierzbicka, Anna. 1992. Semantics, Culture and Coqnition, Universal Human Concept in Culture-Specific Configurations. Oxford: Oxford University Press.

Zoest, Aart van. 1993. Semiotika, Tentang Tanda, Cara Kerjanya dan Apa yang Kita Lakukan Dengannya. Jakarta: Yayasan Sumber Agung. 
Zoest, Aart van \& Sudjiman, Panuti (Peny.). 1996. Serba-Serbi Semiotika. Jakarta: Gramedia. 